\title{
Matching, Stability, and Vibration Analysis of Nonlinear Suspension System for Truck Cabs
}

\author{
Fuxing Yang, ${ }^{1}$ Leilei Zhao ${ }^{D},{ }^{2}$ Yuewei $Y{ }^{2},{ }^{2}$ and Changcheng Zhou ${ }^{2}$ \\ ${ }^{1}$ School of Automation, Beijing University of Posts and Telecommunications, Beijing 100876, China \\ ${ }^{2}$ School of Transportation and Vehicle Engineering, Shandong University of Technology, Zibo 255000, China \\ Correspondence should be addressed to Leilei Zhao; zhaoleilei611571@163.com
}

Received 7 July 2019; Accepted 16 September 2019; Published 7 October 2019

Academic Editor: Paola Forte

Copyright (c) 2019 Fuxing Yang et al. This is an open access article distributed under the Creative Commons Attribution License, which permits unrestricted use, distribution, and reproduction in any medium, provided the original work is properly cited.

\begin{abstract}
To improve comfort, a nonlinear suspension system is proposed on the basis of the nonlinear vibration isolation theory and the installation space of the cab suspension system for trucks. This system is suitable for all-floating cabs. For easy matching and design, the static and stability characteristics of the suspension system were analyzed, respectively, and the boundary condition for the stability of the system was given. Moreover, the cab simulation model was established, and the dynamic simulation was conducted. The stability analysis shows that the smaller the vibration excitation of the cab system, the higher its stability is. The dynamic simulation results show that the acceleration of the cab with the nonlinear suspension system is effectively suppressed; the dynamic deflection of the suspension is kept within a certain range, and the design space of the suspension stroke can be effectively utilized. Compared with the traditional linear suspension system, the nonlinear suspension system has better vibration isolation characteristics and can effectively improve ride comfort.
\end{abstract}

\section{Introduction}

Transportation industry plays an important role in the national economy of any country. As the main body of the transport industry, the stability and ride comfort of trucks have attracted much attention $[1,2]$. The suspension system of truck cabs, as one of the main vibration isolation systems, directly affects the ride comfort of drivers. Scholars have conducted a large number of theoretical and experimental studies on this issue [3-5].

The vibration isolation system for cabs has various forms. With the continuous improvement of driving comfort requirements, the all-floating cab has become gradually popular [6]. The air suspension system is only used in the cab of the high-end vehicles because of its high price. The common coil springs or rubber springs are usually used in the suspension system of the cab for ordinary vehicles. However, their high dynamic stiffness and poor lowfrequency vibration isolation result in poor ride comfort.
Previous studies on cab vibration of commercial vehicles mostly focused on the optimization of passive suspensions $[7,8]$. In order to improve vehicle comfort, some scholars have adopted active or semiactive control methods $[9,10]$, but they have not been applied in practice for many years. For passive suspensions, if their stiffness is larger, the ride comfort will be worse; if their stiffness is smaller, the suspension deflection will be larger. The high static stiffness and low-dynamic stiffness suspension is an effective solution to the above contradictions. The design of many systems involves stability issues $[11,12]$. In the design of such suspension systems, attention should be paid to the stability of the system.

Many scholars have conducted a lot of research on the vibration isolation system with high static stiffness and low dynamic stiffness. The most typical structure consists of two oblique springs and one vertical linear spring [13]. Some scholars also applied active control method [14] and new materials [15] to generate negative stiffness, so as to 
enhance the isolation performance of the vibration isolation system. Zhou et al. [16] analyzed the nonlinear dynamic characteristics of a quasi-zero-stiffness vibration isolator. Huang et al. [17] proposed a method to design a quasi-zero-stiffness system by the parallel connection of the linear spring and the Euler buckling beam with negative stiffness. Meng et al. [18] proposed a design of a quasi-zerostiffness isolator based on a disk spring and studied the influence of system parameters on the force transfer rate by means of the average method. Le et al. [19] designed a quasi-zero-stiffness vibration isolation system by parallel connection of two connecting rods and springs, applied it to the vibration isolation of automobile seats, and achieved good vibration isolation effect. Xu et al. [20] designed a low frequency vibration isolator with quasi-zero-stiffness characteristics by using the magnetic spring. Carrella et al. [21] designed a vibration isolation system with high static stiffness and low dynamic stiffness by combining the linear spring and the magnet spring. In [22], a method for obtaining negative stiffness by using the nonlinear interval of hyperelastic materials was proposed. A method of generating negative stiffness by using the magnetic nonlinearity was proposed in [23]. Zhou et al. researched a novel quasi-zero-stiffness strut and its applications [24, 25]. In [26], a Stewart isolator with negative stiffness magnetic springs was analyzed.

Previous studies have mostly focused on the form, principle, and characteristics of the quasi-zero-stiffness isolators and rarely applied them to the cab vibration isolation system. Based on the nonlinear vibration isolation theory and the installation space of the suspension system, this paper applied the nonlinear suspension system to the all-floating cab. Moreover, its static and stability characteristics were analyzed, respectively. The simulation model of the truck cab was established by using MATLAB software, and the comfort simulation was carried out.

\section{The Cab with the Nonlinear Suspension System}

Figure 1 shows the nonlinear suspension system for truck cabs, which consists of the front suspension and the rear suspension. " $l_{i j}$ " denotes the distance from the mounting point of the suspension to the cab mass center. " $i$ " denotes " $f$ " and " $r$," respectively; " $j$ " denotes " $R$ " and " $L$," respectively; " $f$," " $r$," " $R$," and " $L$ " denotes front, rear, right, and left, respectively. Each suspension uses a pair of transverse linear springs to generate negative stiffness in the vertical direction, and a quasi-zero-stiffness vibration isolation system is formed in parallel with the vertical positive stiffness linear springs. At the static equilibrium position, the negative stiffness produced by the negative stiffness adjusting mechanism and the positive stiffness produced by the vertical spring cancel each other, and the quasi-zero-stiffness characteristic can be obtained [27].

In order to facilitate engineering application, the original cab system is equivalent to four single-degree-offreedom systems, and matching research is carried out

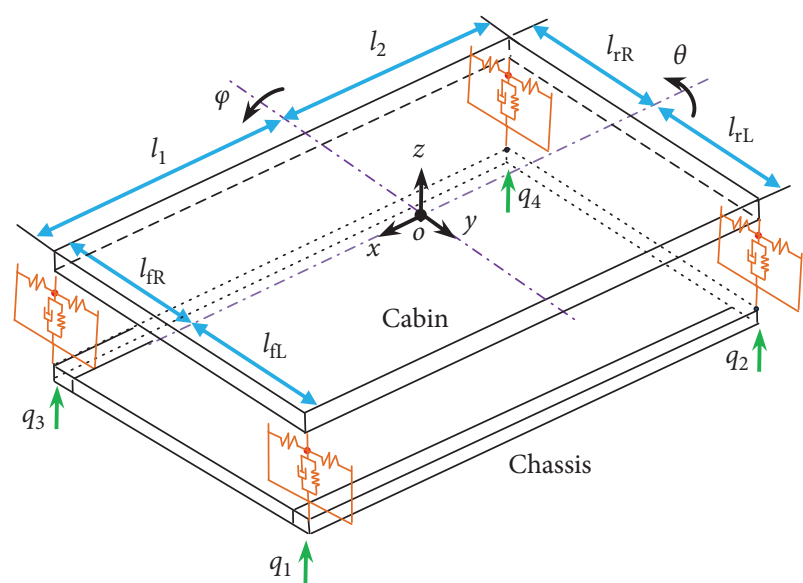

FIgURE 1: The cab with the nonlinear suspension system.

separately. The equivalent system is shown in Figure 2, where $m_{i}$ is the equivalent spring mass of the $i$ th suspension system; $K_{\mathrm{H}}$ is the stiffness of the transverse spring; $L_{\mathrm{H}}$ is the installation space of the transverse spring; $K_{\mathrm{V}}$ is the stiffness of the vertical spring; $C$ is the damping coefficient of the suspension system; $z_{i}$ is the vertical displacement of the $i$ th equivalent spring mass; and $q_{i}$ is the vertical displacement excitation of the $i$ th suspension system.

\section{Matching and Static Characteristic Analysis of the Nonlinear Suspension System}

The matching and the static characteristics of the nonlinear suspension system are important considerations in the cab design. After the suspension space structure and the performance parameters are determined, the dynamic characteristics of the system are determined accordingly. Therefore, first of all, it is necessary to match the structure and performance parameters of the mount system.

3.1. Matching of the Nonlinear Suspension System. When the cab weight is applied to the suspension system, the mass supported by each suspension can be obtained by force analysis:

$$
\begin{aligned}
& m_{\mathrm{fL}}=\frac{m l_{2} l_{\mathrm{fR}}}{\left(l_{1}+l_{2}\right)\left(l_{\mathrm{fL}}+l_{\mathrm{fR}}\right)}, \\
& m_{\mathrm{fR}}=\frac{m l_{2} l_{\mathrm{fL}}}{\left(l_{1}+l_{2}\right)\left(l_{\mathrm{fL}}+l_{\mathrm{fR}}\right)}, \\
& m_{\mathrm{rL}}=\frac{m l_{1} l_{\mathrm{fR}}}{\left(l_{1}+l_{2}\right)\left(l_{\mathrm{fL}}+l_{\mathrm{fR}}\right)}, \\
& m_{\mathrm{rR}}=\frac{m l_{1} l_{\mathrm{rL}}}{\left(l_{1}+l_{2}\right)\left(l_{\mathrm{fL}}+l_{\mathrm{fR}}\right)} .
\end{aligned}
$$

In practical engineering applications, it can be approximately considered that the center of the cab mass coincides with the geometric center, thus 


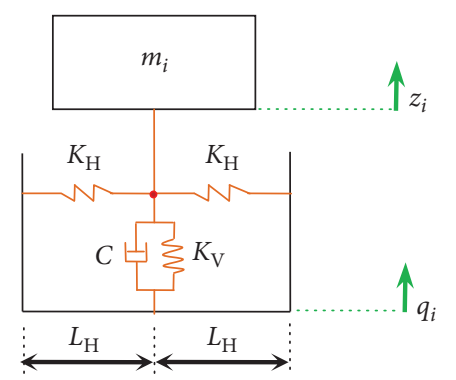

FIGURE 2: The equivalent suspension system.

$$
m_{\mathrm{fL}}=m_{\mathrm{fR}}=m_{\mathrm{rL}}=m_{\mathrm{rR}}=\frac{m}{4}=m_{0}
$$

After static balance, the transverse spring is just in the horizontal position (recorded as the equilibrium position). The relationship between the compression value $L_{V}$, the equivalent mass $m_{i}$, and the vertical spring stiffness $K_{\mathrm{V}}$ can be expressed as follows:

$$
K_{\mathrm{V}} L_{\mathrm{V}}=m_{i} g .
$$

According to the vertical motion space of the cab, $L_{\mathrm{V}}$ can be determined. According to equation (3), $K_{\mathrm{V}}$ can be determined as

$$
K_{\mathrm{V}}=\frac{m_{i} g}{L_{\mathrm{V}}}
$$

According to the lateral mounting space of the transverse spring, $L_{\mathrm{H}}$ can be determined. According to the geometric relationship, the original length $L_{0}$ of the transverse spring can be determined by comparing before and after static balance:

$$
L_{0}=\sqrt{L_{\mathrm{V}}^{2}+L_{\mathrm{H}}^{2}}
$$

According to the geometric relationship, when the relative motion between the frame and the cab occurs, the relative displacement $u$ can be expressed as

$$
u=z_{i}-q_{i}
$$

According to the principle of virtual work, when the relative displacement $u$ occurs, the relationship between the elastic vertical force $F$ and the relative displacement $u$ of the nonlinear suspension system cab be expressed as follows:

$$
F=K_{\mathrm{V}} u+2 K_{\mathrm{H}}\left(1-\frac{\sqrt{L_{\mathrm{V}}^{2}+L_{\mathrm{H}}^{2}}}{\sqrt{u^{2}+L_{\mathrm{H}}^{2}}}\right) u .
$$

For the traditional linear suspension system, the relationship between the vertical elastic force $F$ and the displacement $u$ of the linear suspension system is as follows:

$$
F^{\prime}=K_{\mathrm{V}} u
$$

The stiffness characteristics of the nonlinear suspension system can be obtained by calculating the derivative of $F$ to $u$ by equation (7):

$$
K=K_{\mathrm{V}}+2 K_{\mathrm{H}}\left[1-\frac{\sqrt{L_{\mathrm{V}}^{2}+L_{\mathrm{H}}^{2}} L_{\mathrm{H}}^{2}}{\left(u^{2}+L_{\mathrm{H}}^{2}\right)^{3 / 2}}\right]
$$

Let $z=0$, the stiffness $K_{\mathrm{e}}$ of the nonlinear suspension system at the static equilibrium position can be expressed as

$$
K_{\mathrm{e}}=K_{\mathrm{V}}+2 K_{\mathrm{H}}\left[1-\frac{\sqrt{L_{\mathrm{V}}^{2}+L_{\mathrm{H}}^{2}}}{L_{\mathrm{H}}}\right] \text {. }
$$

According to the natural frequency $f_{i}$ required by the suspension system, the value of $K_{\mathrm{e}}$ can be determined as

$$
K_{\mathrm{e}}=m_{i}\left(2 \pi f_{i}\right)^{2} \text {. }
$$

According to the value of $K_{\mathrm{e}}$ and equations (10) and (11), the stiffness $K_{\mathrm{H}}$ of the transverse spring can be determined as

$$
K_{\mathrm{H}}=\frac{m_{i}\left(2 \pi f_{i}\right)^{2}-K_{\mathrm{V}}}{2\left[1-\left(\sqrt{L_{\mathrm{V}}^{2}+L_{\mathrm{H}}^{2}} / L_{\mathrm{H}}\right)\right]} .
$$

In special cases, in order to achieve zero stiffness at the equilibrium position, $K_{\mathrm{e}}=0$, so the stiffness of the transverse spring can be further expressed as

$$
K_{\mathrm{H}}=\frac{K_{\mathrm{V}}}{2\left[\left(\sqrt{L_{\mathrm{V}}^{2}+L_{\mathrm{H}}^{2}} / L_{\mathrm{H}}\right)-1\right]} .
$$

From equation (9), we obtain the following:

$$
K-K_{\mathrm{V}}=2 K_{\mathrm{H}}\left[1-\frac{\sqrt{L_{\mathrm{V}}^{2}+L_{\mathrm{H}}^{2}} L_{\mathrm{H}}^{2}}{\left(u^{2}+L_{\mathrm{H}}^{2}\right)^{3 / 2}}\right] \text {. }
$$

Let $K-K_{\mathrm{V}} \leq 0$ and based on equation (14), the interval that the stiffness of the nonlinear suspension is less than that of the linear suspension can be obtained as

$$
-\sqrt{\left(\sqrt{L_{\mathrm{V}}^{2}+L_{\mathrm{H}}^{2}} L_{\mathrm{H}}^{2}\right)^{2 / 3}-L_{\mathrm{H}}^{2}} \leq u \leq \sqrt{\left(\sqrt{L_{\mathrm{V}}^{2}+L_{\mathrm{H}}^{2}} L_{\mathrm{H}}^{2}\right)^{2 / 3}-L_{\mathrm{H}}^{2}} \text {. }
$$

The interval that the stiffness of the nonlinear suspension is larger than that of the linear suspension can be obtained as

$$
\begin{gathered}
-L_{\mathrm{H}} \leq u \leq-\sqrt{\left(\sqrt{L_{\mathrm{V}}^{2}+L_{\mathrm{H}}^{2}} L_{\mathrm{H}}^{2}\right)^{2 / 3}-L_{\mathrm{H}}^{2}}, \\
\sqrt{\left(\sqrt{L_{\mathrm{V}}^{2}+L_{\mathrm{H}}^{2}} L_{\mathrm{H}}^{2}\right)^{2 / 3}-L_{\mathrm{H}}^{2}} \leq u \leq L_{\mathrm{H}} .
\end{gathered}
$$

For example, in order to improve the comfort of a heavy truck, the nonlinear suspension system for the cab can be matched according to the method provided in this study. The cab mass center and the geometric center approximately coincide. The cab mass $m$ equals $880 \mathrm{~kg}$. According to the installation space requirement of the suspension system, we can determine $L_{\mathrm{V}}=45 \mathrm{~mm}$ and $L_{\mathrm{H}}=60 \mathrm{~mm}$. In order to achieve zero stiffness at static equilibrium position, $K_{\mathrm{H}}=95.82 \mathrm{~N} / \mathrm{mm}$ and $K_{\mathrm{V}}=47.91 \mathrm{~N} / \mathrm{mm}$ are determined, respectively. Figure 3 is the relationship curve between the 
vertical elastic force $F$ and the displacement $u$ of the suspension system. From Figure 3, it can be seen that near the equilibrium position, the stiffness of the nonlinear suspension system is close to zero. When $u \in[-24,24] \mathrm{mm}$, the dynamic stiffness of the nonlinear suspension system is lower than that of the traditional linear suspension system, which can attenuate the cab vibration better. When $u<[-45$, -24] $\mathrm{mm}$ or $u<[24,45] \mathrm{mm}$, the dynamic stiffness of the nonlinear suspension system is greater than that of the traditional linear suspension system, which can better limit the large-scale vibration of the cab.

3.2. Influence of System Parameters on Static Characteristics. According to the matching method mentioned above, the static characteristics of the nonlinear suspension system are affected by the natural frequency $f_{i}$, the compression value $L_{\mathrm{V}}$, and the installation space $L_{\mathrm{H}}$ of the transverse spring. In order to grasp the influence of parameters on the static characteristics, Figure 4 was drawn based on equation (9). Figure 4(a) shows that with the increase of the natural frequency $f_{i}$ of the static equilibrium position, the lowfrequency vibration isolation region $[-24,24] \mathrm{mm}$ remains unchanged, but the stiffness of the region increases and that of other regions decreases. From Figure 4(b), it can be seen that increasing the installation space $L_{\mathrm{H}}$ of the transverse spring is helpful in reducing the stiffness of the low-frequency vibration isolation area. From Figure 4(c), it can be seen that increasing the compression value $L_{\mathrm{V}}$ is helpful in reducing the stiffness of the low-frequency vibration isolation region, but the stiffness of the limit region is also reduced.

\section{Analysis of Amplitude-frequency Characteristics and Stability}

Let the exact analytical expression of the nonlinear spring force be $F(u)$, then the Taylor expansion of $F(u)$ at $u=u_{0}$ is expressed as

$$
F(u)=F\left(u_{0}\right)+\sum_{n=1}^{N} \frac{F^{(n)}\left(u_{0}\right)}{n !}\left(u-u_{0}\right)^{n} .
$$

In order to explore the inherent characteristics of the cab with the nonlinear suspension system, the third-order Taylor expansion of $F(u)$ is adopted in this study:

$$
F(u) \approx F(0)+\sum_{n=1}^{3} \frac{F^{(n)}(0)}{n !}(u-0)^{n} .
$$

Therefore, the relationship between the elastic vertical force $F$ and the displacement $u$ of the nonlinear suspension system can be approximately expressed as

$$
F(u)=k_{1} u+k_{3} u^{3},
$$

where $\quad k_{1}=K_{\mathrm{V}}+2\left(1-\left(\sqrt{L_{\mathrm{V}}^{2}+L_{\mathrm{H}}^{2}} / L_{\mathrm{H}}\right)\right) K_{\mathrm{H}}$ and $k_{3}=\left(\sqrt{L_{\mathrm{V}}^{2}+L_{\mathrm{H}}^{2}} / L_{\mathrm{H}}^{3}\right) K_{\mathrm{H}}$.

A comparison of the curves between the elastic vertical force $F$ and the displacement $u$ of the nonlinear suspension system determined by formulas (7) and (19) is shown in
Figure 5. By comparison, the approximate curve can approximate the exact curve better. Therefore, it is feasible to approximate the exact analytical expression of the nonlinear spring force by using the third-order Taylor expansion.

From Figure 2, the vibration equation of the equivalent cab system can be obtained as follows:

$$
m \frac{\mathrm{d}^{2} z}{\mathrm{~d} t^{2}}+F(u)+c \frac{\mathrm{d} u}{\mathrm{~d} t}=0 .
$$

Substituting equations (6) and (19) into equation (20), we obtain the following:

$$
m\left(\frac{\mathrm{d}^{2} u}{\mathrm{~d} t^{2}}+\frac{\mathrm{d}^{2} q}{\mathrm{~d} t^{2}}\right)+k_{1} u+k_{3} u^{3}+c \frac{\mathrm{d} u}{\mathrm{~d} t}=0 .
$$

Equation (21) can be further expressed as

$$
m \frac{\mathrm{d}^{2} u}{\mathrm{~d} t^{2}}+k_{1} u+k_{3} u^{3}+c \frac{\mathrm{d} u}{\mathrm{~d} t}=-m \frac{\mathrm{d}^{2} q}{\mathrm{~d} t^{2}} .
$$

Suppose the excitation of the frame is

$$
\frac{\mathrm{d}^{2} q}{\mathrm{~d} t^{2}}=-Y_{0} \cos (\omega t+\varphi),
$$

where $Y_{0}$ is the vibration acceleration amplitude of the frame.

Substituting equation (23) into equation (22), we obtain the following:

$$
m \frac{\mathrm{d}^{2} u}{\mathrm{~d} t^{2}}+c \frac{\mathrm{d} u}{\mathrm{~d} t}+k_{1} u+k_{3} u^{3}=m Y_{0}(\omega t+\varphi) .
$$

By the identical transformation of equation (24), we obtain the following:

$$
\frac{\mathrm{d}^{2} u}{\mathrm{~d} t^{2}}+\frac{c}{m} \frac{\mathrm{d} u}{\mathrm{~d} t}+\frac{k_{1}}{m} u+\frac{k_{3}}{m} u^{3}=Y_{0} \cos (\omega t+\varphi) .
$$

By the variable substitution for equation (25), we obtain the following:

$$
\frac{\mathrm{d}^{2} u}{\mathrm{~d} t^{2}}+2 n \frac{\mathrm{d} u}{\mathrm{~d} t}+p^{2} u+\varepsilon u^{3}=Y_{0} \cos (\omega t+\varphi),
$$

where $n$ is the attenuation coefficient, $p$ is the undamped natural frequency, and $2 n=c / m, p^{2}=k_{1} / m$, and $\varepsilon=k_{3} / m$.

Suppose the principal resonance response near $\omega \approx p$ for equation (26) is as follows:

$$
u=A \cos (\omega t),
$$

where $A$ is the amplitude of the relative displacement $u$ under the simple harmonic oscillation.

Equation (27) is substituted into equation (26), and the third harmonic is ignored. Then, let the corresponding coefficients on both sides equal, we obtain the following equation:

$$
\left\{\begin{array}{l}
\frac{3}{4} \varepsilon A^{3}+\left(p^{2}-\omega^{2}\right) A=Y_{0} \cos (\varphi) \\
2 n \omega A=\omega^{2} \sin (\varphi)
\end{array}\right.
$$




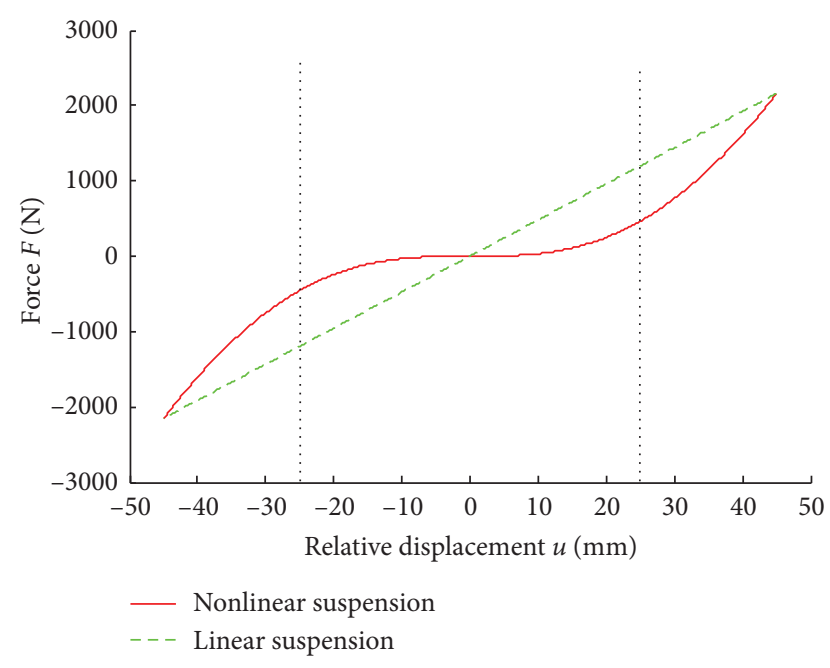

(a)

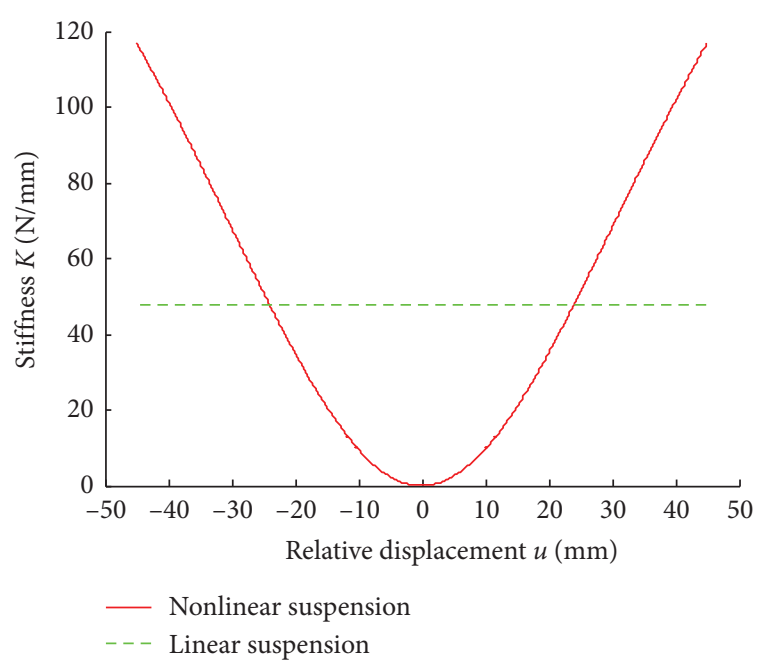

(b)

FIgURE 3: The curves of the nonlinear suspension system: (a) the elastic vertical force $F$ versus the relative displacement $u$ and (b) the suspension stiffness $K$ versus the relative displacement $u$.

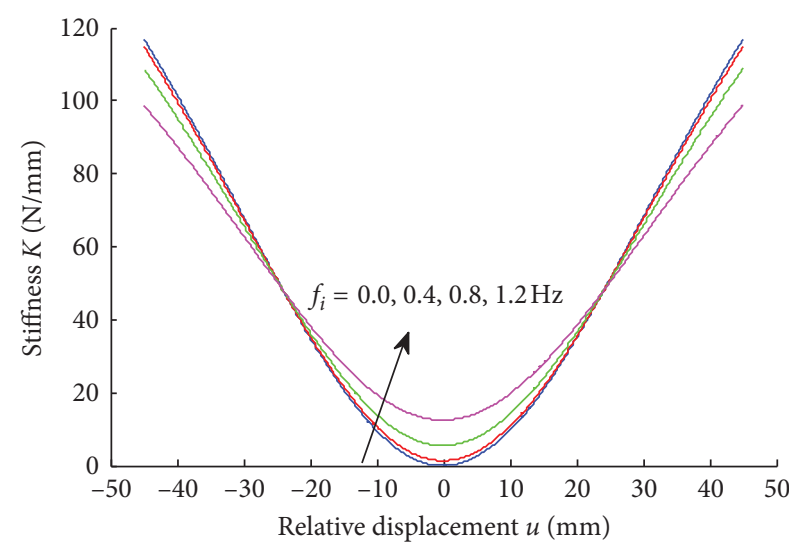

(a)

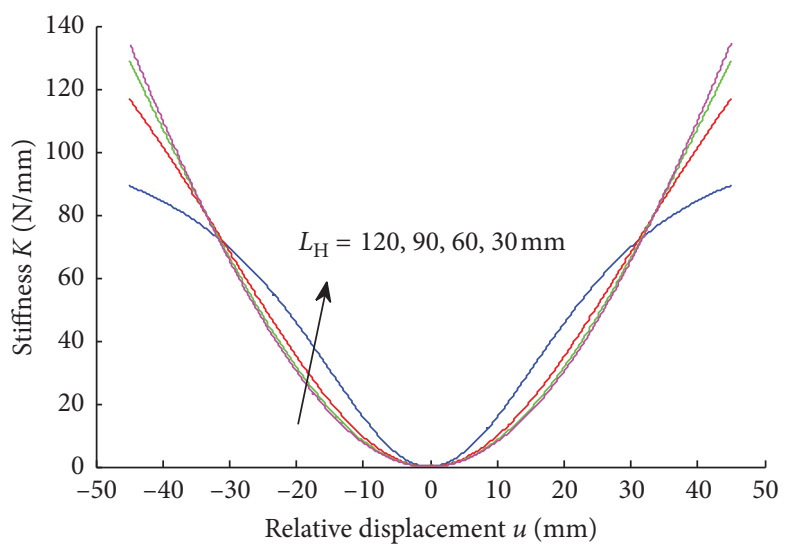

(b)

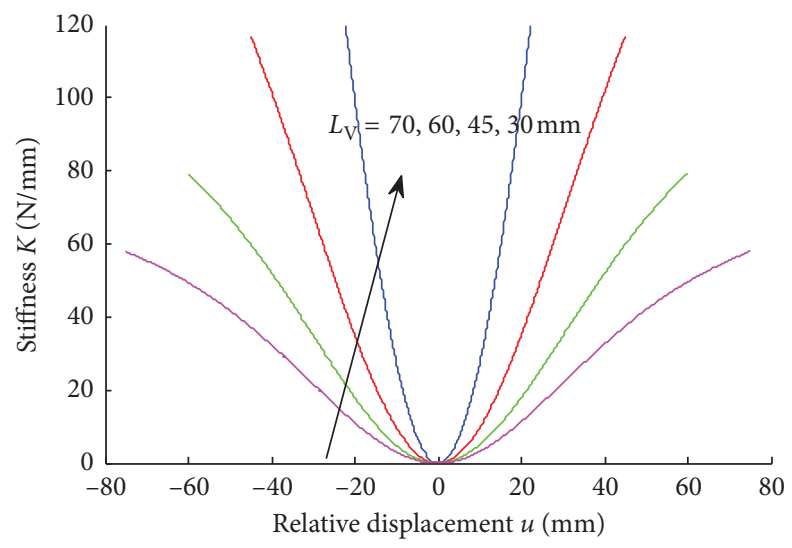

(c)

Figure 4: The curve of $K$ versus $u$ for the nonlinear suspension system: (a) at different values of $f_{i}$, (b) at different values of $L_{\mathrm{H}}$, and (c) at different values of $L_{\mathrm{H}}$. 


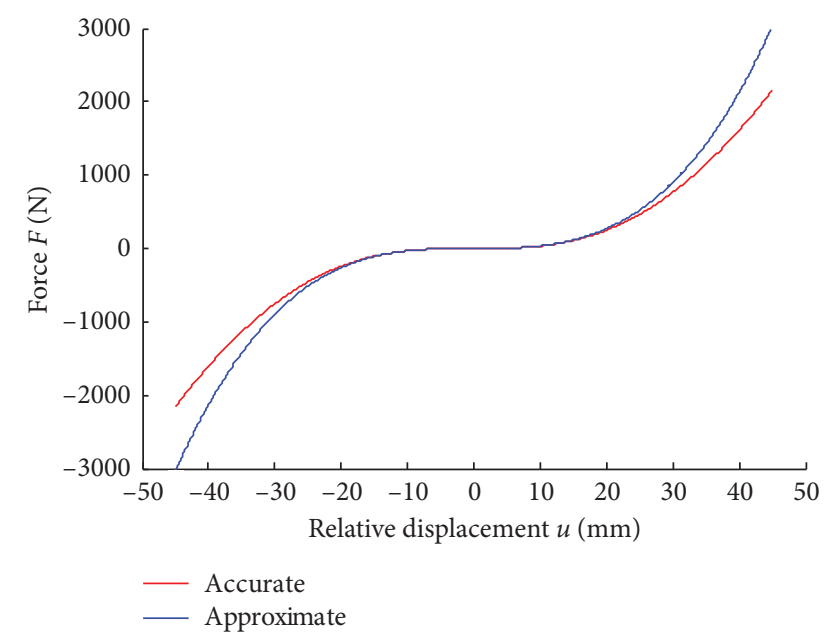

Figure 5: A comparison of the curves between the elastic vertical force $\mathrm{F}$ and the displacement $u$ of the nonlinear suspension system.

Based on equation (28), the equation of amplitudefrequency characteristic curve can be obtained as follows [28]:

$$
\left[\left(p^{2}-\omega^{2}\right) A+\frac{3}{4} \varepsilon A^{3}\right]^{2}+4 n^{2} \omega^{2} A^{2}=Y_{0}^{2} .
$$

Calculating the derivative of equation (29) to $A$, we get

$$
\frac{\mathrm{d}}{\mathrm{d} A}\left(\left[\frac{3}{4} \varepsilon A^{3}+\left(p^{2}-\omega^{2}\right) A\right]^{2}+4 n^{2} \omega^{2} A^{2}\right)=0 .
$$

Simplifying equation (30), we obtain the following:

$$
\left.\left[\frac{3}{4} \varepsilon A^{2}+p^{2}-\omega^{2}\right]\left[\frac{9}{4} \varepsilon A^{2}+p^{2}-\omega^{2}\right]\right]+4 n^{2} \omega^{2}=0 \text {. }
$$

The stability condition of periodic solutions is as follows:

$$
\left[\frac{3}{4} \varepsilon A^{2}+p^{2}-\omega^{2}\right]\left[\frac{9}{4} \varepsilon A^{2}+p^{2}-\omega^{2}\right]+4 n^{2} \omega^{2}>0 .
$$

For example, the amplitude-frequency characteristic curves of the designed cab with the nonlinear suspension system in this paper under different excitation accelerations are shown in Figure 6. To show the advantage of the nonlinear suspension, the characteristic curves of the linear suspension with the vertical stiffness $K_{\mathrm{V}}=47.91 \mathrm{~N} / \mathrm{mm}$ were also plotted in Figure 6 . The analysis shows that with the increase of the excitation intensity, the peak of the vibration response shifts to the right, and the unstable region increases gradually. At the same time, the response amplitude $A$ also increases. Thus, for the cab with the nonlinear suspension system, the smaller the vibration excitation, the better the stability is. In addition, it can also be seen that the response amplitude $A$ of the nonlinear suspension is obviously less than that of the linear suspension for $Y_{0}=20 \mathrm{~m} / \mathrm{s}^{2}$ in the range of $0 \sim 2.5 \mathrm{~Hz}$; for the response amplitude $A$, there is a slight difference between the two suspensions for $Y_{0}=10 \mathrm{~m} / \mathrm{s}^{2}$. The results show that, in the stable region, when the excitation is larger, the advantages of the nonlinear suspension are more obvious.

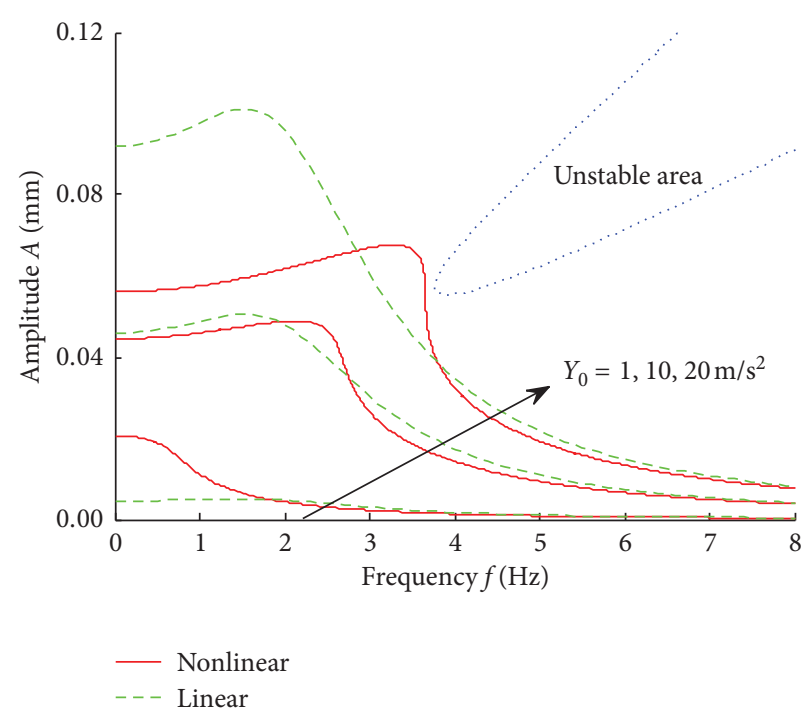

FIgURE 6: The amplitude-frequency characteristic curves of the designed cab with the nonlinear suspension system.

\section{Dynamic Modelling}

The cab system is a very complex multi-degree-of-freedom elastic structure. In order to compare and verify the isolation effect of the nonlinear suspension, a 3-DOF (degree-of-freedom) model of the cab system is considered in this paper. According to Figure 1, the differential equations of the vibration system can be obtained as follows:

$$
\begin{aligned}
m \frac{\mathrm{d}^{2} z_{\mathrm{c}}}{\mathrm{d} t^{2}}= & -F_{1}-c_{1}\left(\frac{\mathrm{d} z_{1}}{\mathrm{~d} t}-\frac{\mathrm{d} q_{1}}{\mathrm{~d} t}\right)-F_{3}-c_{3}\left(\frac{\mathrm{d} z_{3}}{\mathrm{~d} t}-\frac{\mathrm{d} q_{3}}{\mathrm{~d} t}\right) \\
& -F_{2}-c_{2}\left(\frac{\mathrm{d} z_{2}}{\mathrm{~d} t}-\frac{\mathrm{d} q_{2}}{\mathrm{~d} t}\right)-F_{4}-c_{4}\left(\frac{\mathrm{d} z_{4}}{\mathrm{~d} t}-\frac{\mathrm{d} q_{4}}{\mathrm{~d} t}\right), \\
I_{x} \frac{\mathrm{d}^{2} \theta}{\mathrm{d} t^{2}}= & -\left[F_{1}+c_{1}\left(\frac{\mathrm{d} z_{1}}{\mathrm{~d} t}-\frac{\mathrm{d} q_{1}}{\mathrm{~d} t}\right)\right] l_{\mathrm{fL}}+\left[F_{3}+c_{3}\left(\frac{\mathrm{d} z_{3}}{\mathrm{~d} t}-\frac{\mathrm{d} q_{3}}{\mathrm{~d} t}\right)\right] l_{\mathrm{fR}} \\
& -\left[F_{2}+c_{2}\left(\frac{\mathrm{d} z_{2}}{\mathrm{~d} t}-\frac{\mathrm{d} q_{2}}{\mathrm{~d} t}\right)\right] l_{\mathrm{rL}}+\left[F_{4}+c_{4}\left(\frac{\mathrm{d} z_{4}}{\mathrm{~d} t}-\frac{\mathrm{d} q_{4}}{\mathrm{~d} t}\right)\right] l_{\mathrm{rR}}, \\
I_{y} \frac{\mathrm{d}^{2} \varphi}{\mathrm{d} t^{2}=} & {\left[F_{1}+c_{1}\left(\frac{\mathrm{d} z_{1}}{\mathrm{~d} t}-\frac{\mathrm{d} q_{1}}{\mathrm{~d} t}\right)\right] l_{1}+\left[F_{3}+c_{3}\left(\frac{\mathrm{d} z_{3}}{\mathrm{~d} t}-\frac{\mathrm{d} q_{3}}{\mathrm{~d} t}\right)\right] l_{1} } \\
& -\left[F_{2}+c_{2}\left(\frac{\mathrm{d} z_{2}}{\mathrm{~d} t}-\frac{\mathrm{d} q_{2}}{\mathrm{~d} t}\right)\right] l_{2}-\left[F_{4}+c_{4}\left(\frac{\mathrm{d} z_{4}}{\mathrm{~d} t}-\frac{\mathrm{d} q_{4}}{\mathrm{~d} t}\right)\right] l_{2},
\end{aligned}
$$

where for the force $F_{i}(i=1,2,3,4)$, when determined by equation (7), it is a nonlinear elastic force and when determined by equation (8), it is a linear elastic force.

According to the above dynamic equations, the $3-\mathrm{DOF}$ simulation model of the cab system is established by using MATLAB software, as shown in Figure 7. On this basis, the performance analysis of the nonlinear suspension system can be carried out. The model parameters used in the analysis are shown in Table 1. 


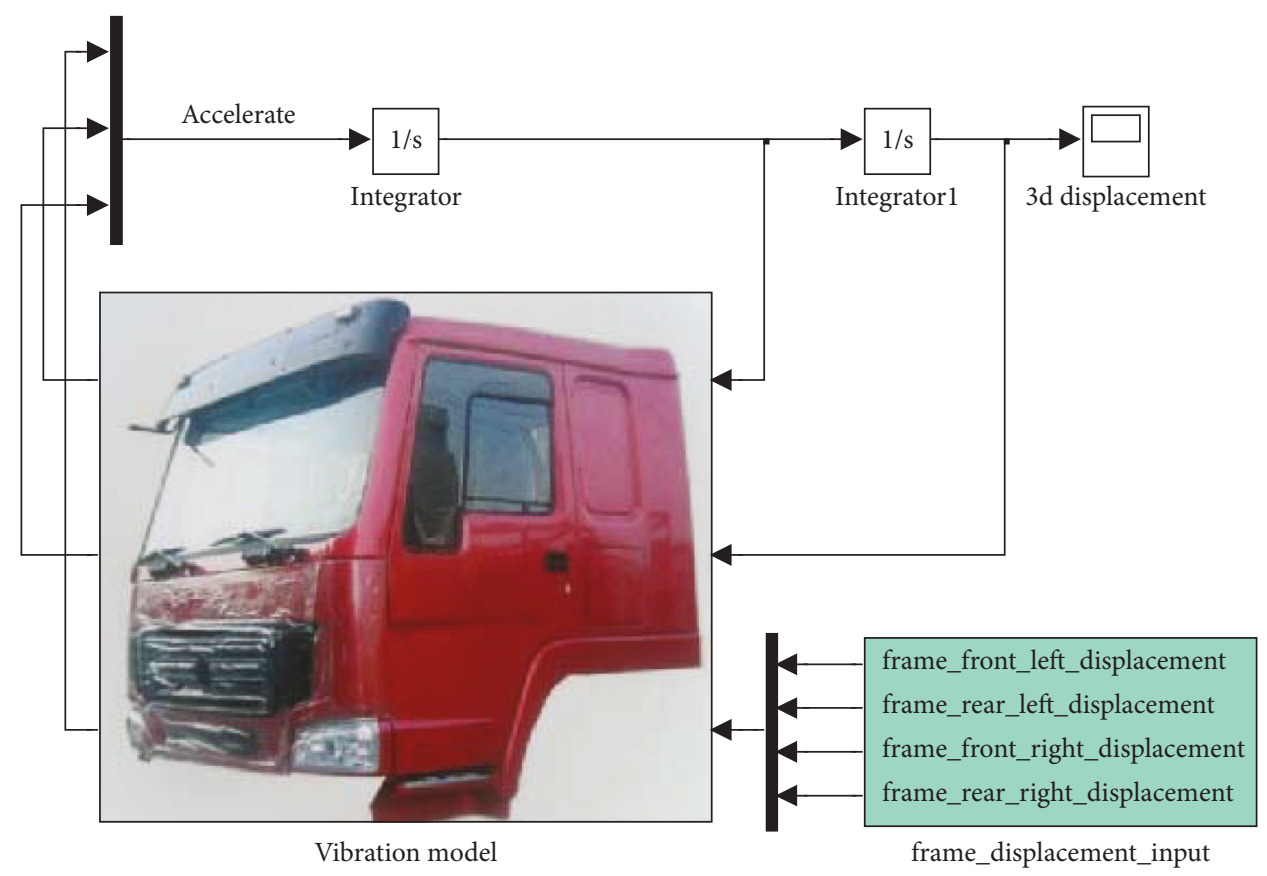

Figure 7: The simulation model.

TABle 1: The mechanical parameters known.

\begin{tabular}{lccc}
\hline Mechanical parameters & Values & Mechanical parameters & Values \\
\hline$m(\mathrm{~kg})$ & 880 & $l_{1}(\mathrm{~m})$ & 0.852 \\
$I_{x}\left(\mathrm{~kg} \cdot \mathrm{m}^{2}\right)$ & 816 & $l_{2}(\mathrm{~m})$ & 0.852 \\
$I_{y}\left(\mathrm{~kg} \cdot \mathrm{m}^{2}\right)$ & 778 & $L_{\mathrm{H}}(\mathrm{m})$ & 0.060 \\
$l_{\mathrm{fL}}(\mathrm{m})$ & 0.542 & $L_{\mathrm{V}}(\mathrm{m})$ & 0.045 \\
$l_{\mathrm{fR}}(\mathrm{m})$ & 0.542 & $K_{\mathrm{H}}(\mathrm{N} / \mathrm{mm})$ & 95.82 \\
$l_{\mathrm{rL}}(\mathrm{m})$ & 0.550 & $K_{\mathrm{V}}(\mathrm{N} / \mathrm{mm})$ & 49.91 \\
$l_{\mathrm{rR}}(\mathrm{m})$ & 0.550 & $c(\mathrm{Ns} / \mathrm{m})$ & 3500 \\
\hline
\end{tabular}

\section{Dynamic Simulation Analysis}

In order to verify the validity and applicability of the cab with the nonlinear suspension system designed in this paper, this section focuses on the analysis of acceleration and suspension travel response characteristics by comparing with the linear suspension system. In this paper, the random vibration signals of the frame collected by a heavy truck driving at a speed of $75 \mathrm{~km} / \mathrm{h}$ on the highway (in [29]) are used as the model excitation.

\subsection{Simulation Analysis of the Cab Vertical Acceleration.} In order to analyze the comfort improvement of the cab with the nonlinear suspension system, the time-domain response and the power spectral density of the cab vertical acceleration were numerically modeled based on the simulation model. In this paper, the time $T=100 \mathrm{~s}$ is chosen to calculate the cab vertical acceleration. The calculation results are shown in Figure 8.

Figure 8(a) shows that compared with the traditional linear suspension, the vertical acceleration of the cab with the nonlinear suspension system decreases significantly and the RMS (root mean square) acceleration value decreases by
$49.1 \%$. Figure 8 (b) shows that the power spectral density of the cab vertical vibration acceleration decreases significantly in the low-frequency stage after the use of the nonlinear suspension. The results show that, in the low-frequency stage, the nonlinear suspension system has good vibration isolation characteristics, which can effectively reduce the cab vibration and improve ride comfort.

6.2. Simulation Analysis of the Suspension Dynamic Deflection. Figure 9 is the simulation result of the suspension dynamic deflection. From Figure 9, it can be seen that the change trend of the travel of the nonlinear suspension is basically the same as that of the linear suspension. The dynamic deflection of each nonlinear suspension is not more than $45 \mathrm{~mm}$, and the travel is within the allowable range. After using the nonlinear suspension system, the dynamic deflection values of the four suspensions increase slightly, thus making full use of the suspension design space. The results show that the nonlinear suspension system can well limit the large-scale motion of the cab and avoid collision with the limit block. Therefore, the proposed engineering design scheme of the nonlinear suspension system for truck cabs is feasible. 


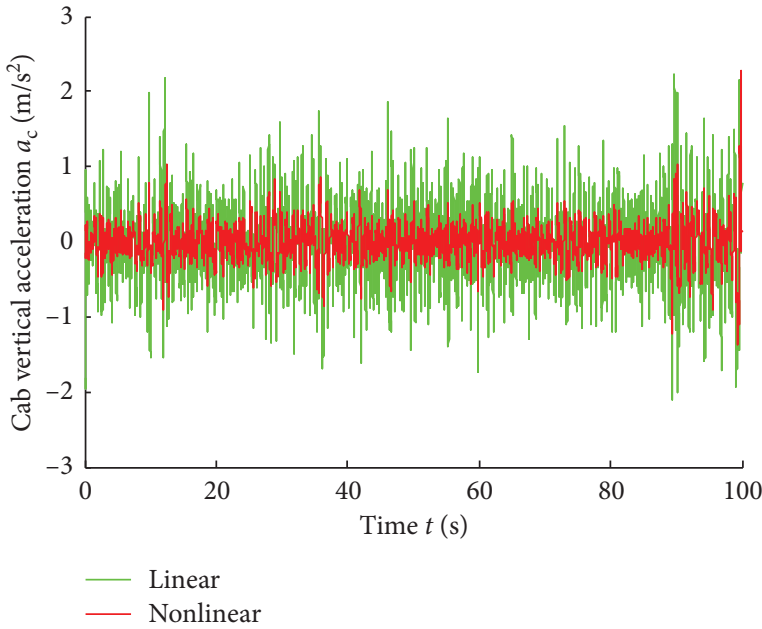

(a)

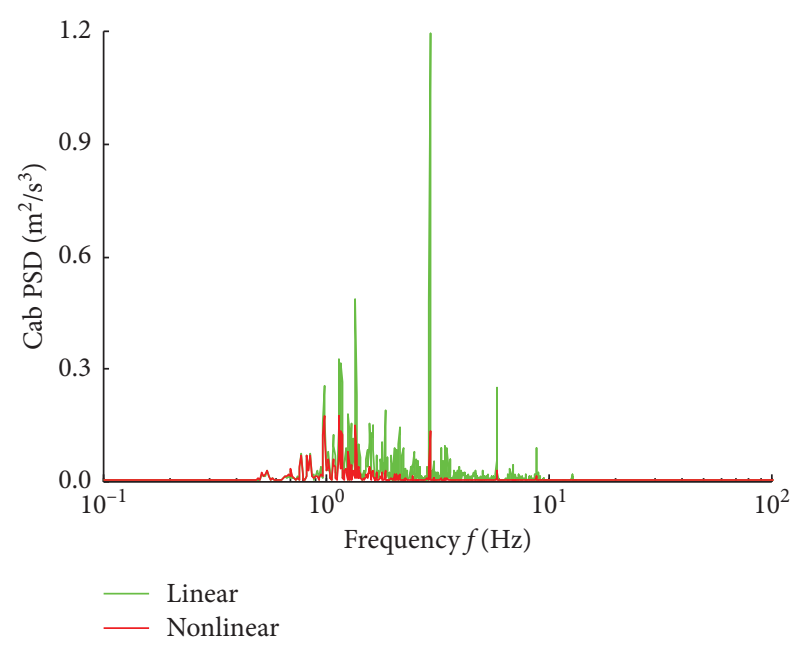

(b)

Figure 8: The cab vertical acceleration: (a) the time-domain response and (b) the power spectral density response.

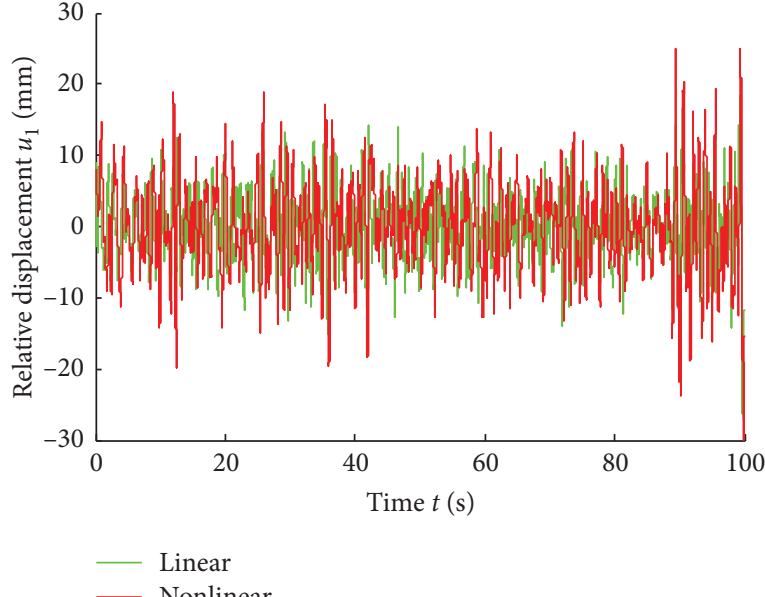

(a)

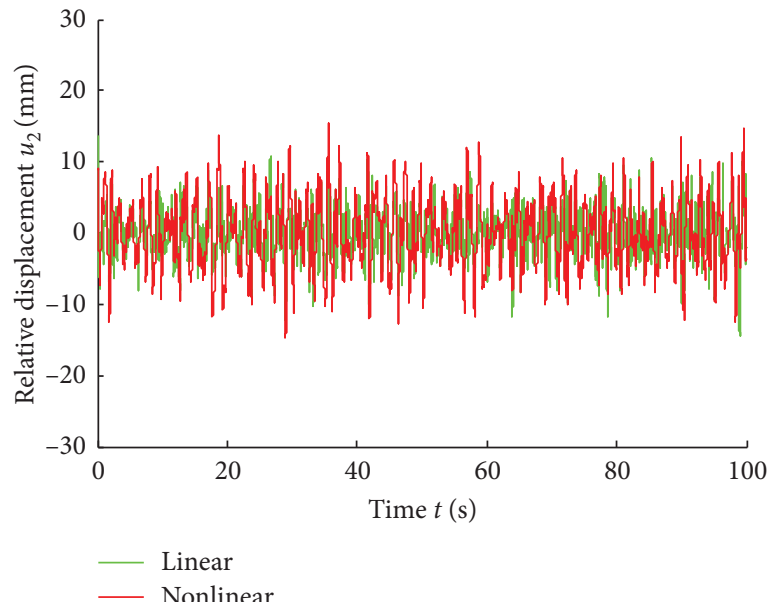

(c)

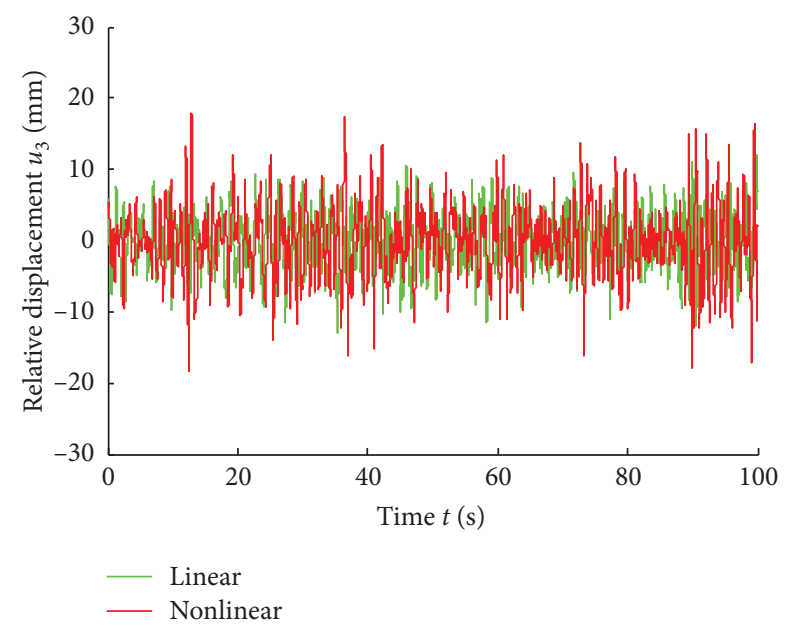

(b)

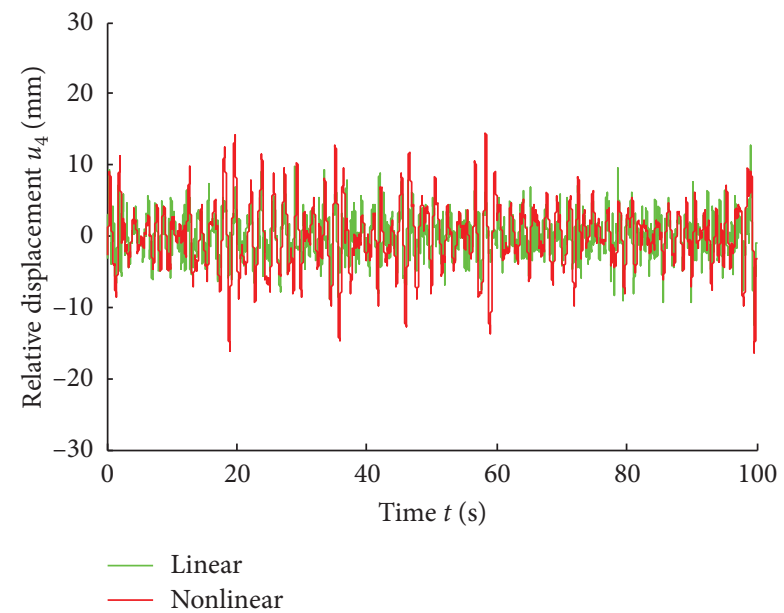

(d)

FIgURE 9: The suspension dynamic deflection responses for (a) the front left suspension, (b) the rear left suspension, (c) the front right suspension, and (d) the rear right suspension. 


\section{Conclusions}

Based on the nonlinear vibration isolation principle, a nonlinear suspension system for the all-floating cab was designed in this paper. The static characteristics and stability of the system were analyzed. The influences of the nonlinear suspension on the mechanical properties of the cab were simulated and analyzed by using MATLAB. Through this study, the following conclusions were drawn:

(1) With the increase of the natural frequency $f_{i}$ of the static equilibrium position, the low-frequency vibration isolation region remains unchanged, but the stiffness of the region increases and that of other regions decreases. Increasing the installation space $L_{\mathrm{H}}$ of the transverse spring is helpful to reduce the stiffness of the low-frequency vibration isolation area. Increasing the compression value $L_{\mathrm{V}}$ is helpful in reducing the stiffness of the low-frequency vibration isolation region, but the stiffness of the limit region is also reduced.

(2) With the increase of the excitation intensity, the peak of the vibration response shifts to the right and the unstable region increases gradually. Meanwhile, the response amplitude $A$ also increases. For the cab with the nonlinear suspension system, the smaller the vibration excitation, the higher the stability is.

(3) Compared with the linear suspension system, the vibration isolation frequency range of the nonlinear suspension system is wider, especially in the lowfrequency stage. It has good vibration isolation characteristics, which can effectively reduce cab vibration and improve ride comfort. Moreover, after using the nonlinear suspension system, the dynamic stiffness of the suspension decreases and the dynamic deflection increases slightly, making full use of the design space of the suspension stroke.

\section{Data Availability}

The data used to support the findings of this study are available from the corresponding author upon request.

\section{Conflicts of Interest}

The authors declare no potential conflicts of interest with respect to the research, authorship, and/or publication of this article.

\section{Acknowledgments}

This research was supported by the National Natural Science Foundation of China (51575325).

\section{References}

[1] M. G. Barker, Puckett, and A. Jay, "Unique truck loads on interstates in Wyoming and similar states and the impact on bridge safety design," Journal of Bridge Engineering, vol. 24, no. 2, pp. 1-10, 2019.
[2] K. Mahajan, N. R. Velaga, A. Kumar, A. Choudhary, and P. Choudhary, "Effects of driver work-rest patterns, lifestyle and payment incentives on long-haul truck driver sleepiness," Transportation Research Part F: Traffic Psychology and Behaviour, vol. 60, pp. 366-382, 2019.

[3] K. Friedman, J. Hutchinson, D. Mihora, S. Kumar, and W. D. Strickland, "Rollover protection for occupants of heavy truck sleeper cabs," International Journal of Crashworthiness, vol. 20, no. 4, pp. 316-324, 2015.

[4] L. L. Zhao, C. C. Zhou, and Y. W. Yu, "Hybrid modeling of seat-cab coupled system for truck," International Journal of Automotive Technology, vol. 17, no. 5, pp. 769-776, 2016.

[5] J. Roy and E. H. Law, "Effect of cab suspension configuration and location on tractor semi-trailer driver comfort," $S A E$ International Journal of Commercial Vehicles, vol. 9, no. 2, pp. 405-416, 2016.

[6] L. Zhao, C. Zhou, Y. Yu, and F. Yang, "Hybrid modelling and damping collaborative optimisation of Five-suspensions for coupling driver-seat-cab system," Vehicle System Dynamics, vol. 54, no. 5, pp. 667-688, 2016.

[7] K. Wang and F. Gao, "Vibration isolation analysis and optimization of commercial vehicle cab suspension system," in SAE Technical Papers, SAE International, Warrendale, PA, USA, 2018.

[8] J. Gu, H. Wang, C. Wang, M. Pang, and X. Jin, "The parameter optimization and performance analysis of the suspension system in the cab of a heavy truck," Computer and Computing Technologies in Agriculture VII, vol. 419, pp. 16-24, 2014.

[9] S. Kyuhyun, L. Hwayoung, W. Y. Ji et al., "Effectiveness evaluation of hydro-pneumatic and semi-active cab suspension for the improvement of ride comfort of agricultural tractors," Journal of Terramechanics, vol. 69, pp. 23-32, 2017.

[10] F. Caffaro, M. M. Cremasco, C. Preti, and E. Cavallo, "Ergonomic analysis of the effects of a telehandler's active suspended cab on whole body vibration level and operator comfort," International Journal of Industrial Ergonomics, vol. 53, pp. 19-26, 2016.

[11] J. J. Qu, Z. J. Ji, C. Lin et al., "Fast consensus seeking on networks with antagonistic interactions," Complexity, vol. 2018, Article ID 7831317, 15 pages, 2018.

[12] H. Y. Ma, X. Jia, N. Cai et al., "Adaptive guaranteed-performance consensus control for multiagent systems with an adjustable convergence speed," Discrete Dynamics in Nature and Society, vol. 2019, Article ID 5190301, 9 pages, 2019.

[13] A. Carrella, M. J. Brennan, I. Kovacic, and T. P. Waters, "On the force transmissibility of a vibration isolator with quasizero-stiffness," Journal of Sound and Vibration, vol. 322, no. 45, pp. 707-717, 2009.

[14] Y. Araki, K. Kimura, T. Asai, T. Masui, T. Omori, and R. Kainuma, "Integrated mechanical and material design of quasi-zero-stiffness vibration isolator with superelastic $\mathrm{Cu}$ Al-Mn shape memory alloy bars," Journal of Sound and Vibration, vol. 358, pp. 74-83, 2015.

[15] I. A. Mahmood and S. O. R. Moheimani, "Making a commercial atomic force microscope more accurate and faster using positive position feedback control," Review of Scientific Instruments, vol. 80, no. 6, pp. 1254-1273, 2009.

[16] J. Zhou, X. Wang, D. Xu, and S. Bishop, "Nonlinear dynamic characteristics of a quasi-zero stiffness vibration isolator with cam-roller-spring mechanisms," Journal of Sound and Vibration, vol. 346, pp. 53-69, 2015.

[17] X. Huang, X. Liu, J. Sun, Z. Zhang, and H. Hua, "Vibration isolation characteristics of a nonlinear isolator using Euler buckled beam as negative stiffness corrector: a theoretical and 
experimental study," Journal of Sound and Vibration, vol. 333, no. 4, pp. 1132-1148, 2014.

[18] L. Meng, J. Sun, and W. Wu, "Theoretical design and characteristics analysis of a quasi-zero stiffness isolator using a disk spring as negative stiffness element," Shock and Vibration, vol. 2015, Article ID 813763, 19 pages, 2015.

[19] T. D. Le and K. K. Ahn, "A vibration isolation system in low frequency excitation region using negative stiffness structure for vehicle seat," Journal of Sound and Vibration, vol. 330, no. 26, pp. 6311-6335, 2011.

[20] D. Xu, Q. Yu, J. Zhou, and S. R. Bishop, "Theoretical and experimental analyses of a nonlinear magnetic vibration isolator with quasi-zero-stiffness characteristic," Journal of Sound and Vibration, vol. 332, no. 14, pp. 3377-3389, 2013.

[21] A. Carrella, M. J. Brennan, and T. P. Waters, "On the design of a high-static-low-dynamic stiffness isolator using linear mechanical springs and magnets," Journal of Sound and Vibration, vol. 315, no. 3, pp. 712-720, 2008.

[22] H.-J. Ahn, S.-H. Lim, and C. Park, "An integrated design of quasi-zero stiffness mechanism," Journal of Mechanical Science and Technology, vol. 30, no. 3, pp. 1071-1075, 2016.

[23] Y. Zheng, X. Zhang, Y. Luo, B. Yan, and C. Ma, "Design and experiment of a high-static-low-dynamic stiffness isolator using a negative stiffness magnetic spring," Journal of Sound and Vibration, vol. 360, pp. 31-52, 2016.

[24] J. X. Zhou, K. Wang, D. L. Xu et al., "A six degrees-of-freedom vibration isolation platform supported by a hexapod of quasizero-stiffness struts," Journal of Vibration and Acoustics, Transactions of the ASME, vol. 139, no. 3, p. 34502, 2017.

[25] J. Zhou, Q. Xiao, D. Xu, H. Ouyang, and Y. Li, "A novel quasizero-stiffness strut and its applications in six-degree-offreedom vibration isolation platform," Journal of Sound and Vibration, vol. 394, pp. 59-74, 2017.

[26] Y. Zheng, Q. Li, B. Yan, Y. Luo, and X. Zhang, "A Stewart isolator with high-static-low-dynamic stiffness struts based on negative stiffness magnetic springs," Journal of Sound and Vibration, vol. 422, pp. 390-408, 2018.

[27] A. Carrella, M. J. Brennan, and T. P. Waters, "Static analysis of a passive vibration isolator with quasi-zero-stiffness characteristic," Journal of Sound and Vibration, vol. 301, pp. 678689, 2007.

[28] X. Zhang and Y. Dong, "Theoretical analysis on force transmissibility and jump phenomena of Duffing spring type vibration isolator," Journal of Shock and Vibration, vol. 31, no. 16, pp. 38-42, 2012.

[29] L. Zhao, C. Zhou, Y. Yu, and F. Yang, "Hybrid modelling and damping collaborative optimisation of Five-suspensions for coupling driver-seat-cab system," Vehicle System Dynamics, vol. 54, no. 5, pp. 667-688, 2016. 


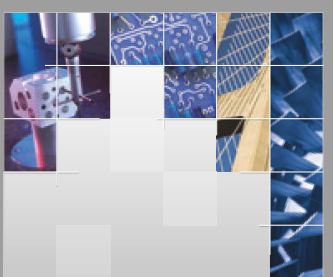

\section{Enfincering}
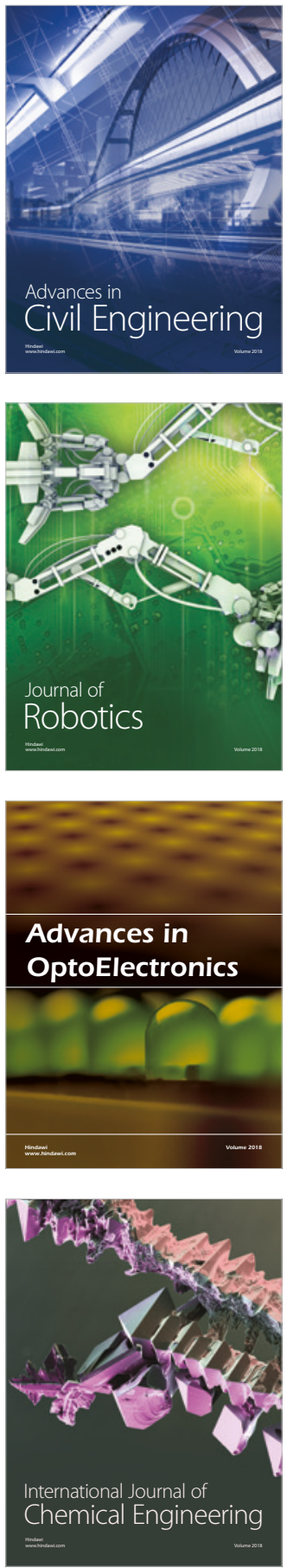

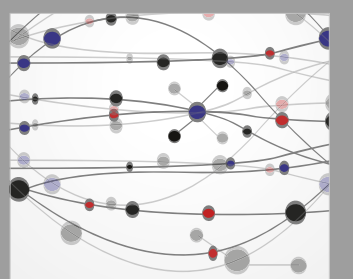

\section{Rotating \\ Machinery}

The Scientific World Journal

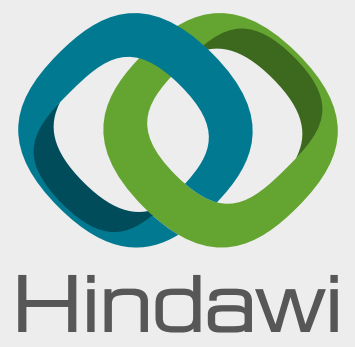

Submit your manuscripts at

www.hindawi.com
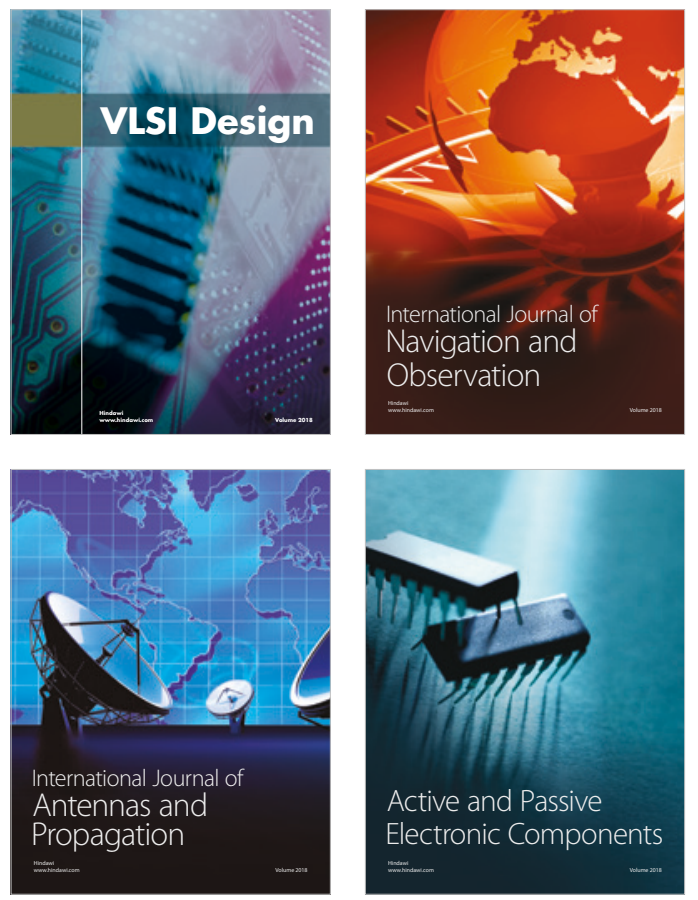
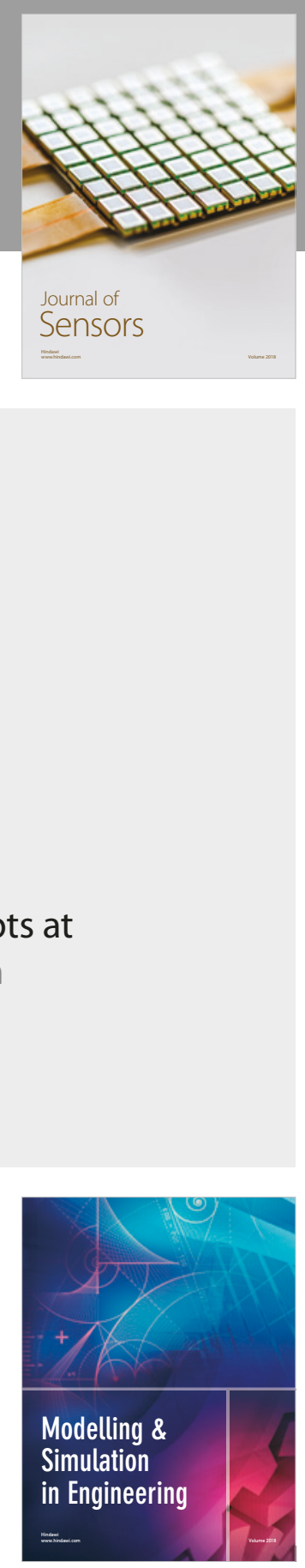

\section{Advances \\ Multimedia}
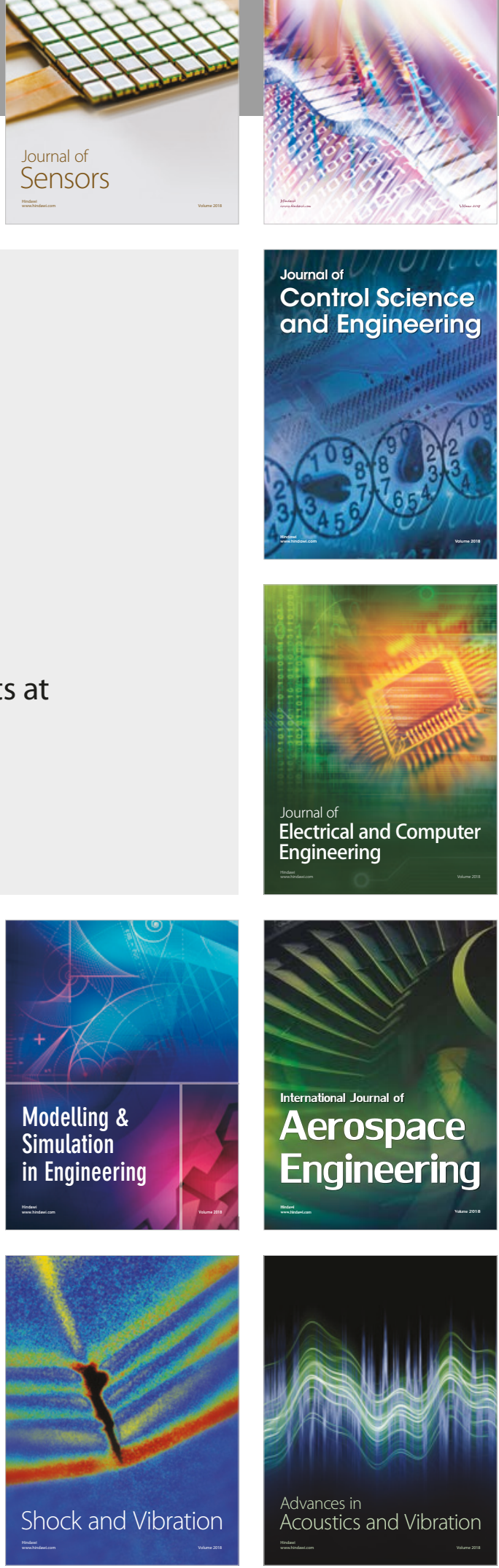